\title{
Resting-State Functional Connectivity Predicts Impulsivity in Economic Decision-Making
}

\author{
Nan Li, ${ }^{1 \star}$ Ning Ma, ${ }^{1 \star}$ Ying Liu,,${ }^{2}$ Xiao-Song He, ${ }^{1}$ De-Lin Sun, ${ }^{1}$ Xian-Ming Fu,,${ }^{2}$ Xiaochu Zhang, ${ }^{1}$ Shihui Han, ${ }^{3}$ \\ and Da-Ren Zhang ${ }^{1}$ \\ ${ }^{1}$ Chinese Academy of Sciences, Key Laboratory of Brain Function and Disease, and School of Life Sciences, University of Science and Technology of China, \\ Hefei, Anhui 230027, China, ${ }^{2}$ Provincial Hospital Affiliated to Anhui Medical University, Hefei, Anhui 230001, China, and ${ }^{3}$ Department of Psychology, \\ Peking University, Beijing 100871, China
}

Increasing neuroimaging evidence suggests an association between impulsive decision-making behavior and task-related brain activity. However, the relationship between impulsivity in decision-making and resting-state brain activity remains unknown. To address this issue, we used functional MRI to record brain activity from human adults during a resting state and during a delay discounting task (DDT) that requires choosing between an immediate smaller reward and a larger delayed reward. In experiment I, we identified four DDTrelated brain networks. The money network (the striatum, posterior cingulate cortex, etc.) and the time network (the medial and dorsolateral prefrontal cortices, etc.) were associated with the valuation process; the frontoparietal network and the dorsal anterior cingulate cortex-anterior insular cortex network were related to the choice process. Moreover, we found that the resting-state functional connectivity of the brain regions in these networks was significantly correlated with participants' discounting rate, a behavioral index of impulsivity during the DDT. In experiment II, we tested an independent group of subjects and demonstrated that this resting-state functional connectivity was able to predict individuals' discounting rates. Together, these findings suggest that resting-state functional organization of the human brain may be a biomarker of impulsivity and can predict economic decision-making behavior.

\section{Introduction}

Delay discounting refers to a phenomenon in economic decisionmaking in which an individual's valuation of a future reward declines as the delay until reward delivery increases (Ainslie, 1975). The mechanism underlying delay discounting has been investigated extensively using a paradigm known as the delay discounting task (DDT) that requires choosing between an immediate smaller reward and a larger delayed reward. An individual's preference for an immediate reward, which can be measured using a behavioral index of discounting rate, characterizes one's impulsivity in decision-making (Green and Myerson, 2004). Discounting rates vary among individuals and are relatively stable over time (Kirby, 2009) and are thus an indicator of trait-level impulsivity in economic decision-making.

\footnotetext{
Received March 19, 2012; revised Dec. 23, 2012; accepted Jan. 18, 2013.

Author contributions: N.L., N.M., and D.-R.Z. designed research; N.L., N.M., Y.L., X.-S.H., and X.-M.F. performed research; N.L., N.M., Y.L., D.-L.S., X.-M.F., and S.H. contributed unpublished reagents/analytic tools; N.L., N.M., X.-S.H., D.-L.S., X.Z., and S.H. analyzed data; N.L., N.M., X.Z., S.H., and D.-R.Z. wrote the paper.

This study was supported by National Nature Science Foundation of China Grants 31000458, 30870764, and 91024025, Fundamental Research Funds for the Central Universities of China Grant WK2070000007, and National Basic Research Program of China 973 Program 2010CB833903. We thank the two anonymous reviewers for their important comments and constructive suggestions on our previous manuscript. We thank Dr. Tianzi Jiang for advice on data analysis and Dr. Michael Varnum for proofreading the manuscript.

The authors declare no competing financial interests.

${ }^{*}$ N.L. and N.M. contributed equally to this work.

Correspondence should be addressed to Da-Ren Zhang, Chinese Academy of Sciences, Key Laboratory of Brain Function and Disease, and School of Life Sciences, University of Science and Technology of China, Huangshan Road 443, Hefei, Anhui 230027, China. E-mail: drzhang@ustc.edu.cn.

DOI:10.1523/JNEUROSCI.1342-12.2013

Copyright $\odot 2013$ the authors $\quad 0270-6474 / 13 / 334886-10 \$ 15.00 / 0$
}

To date, the neural mechanisms underlying impulsivity in decision-making have not been fully understood. Functional magnetic resonance imaging (fMRI) studies have shown evidence for an association between impulsive decision-making behavior and DDT-related brain activation in the frontoparietal regions and the striatum (McClure et al., 2004; Boettiger et al., 2007; Kable and Glimcher, 2007). However, it is not clear whether trait-level impulsivity in decision-making may be related to the functional organization of the brain in a resting state. Resting-state functional connectivity (rsFC), indexed by correlations in low-frequency fluctuation of the resting-state fMRI signal, may characterize the intrinsic functional organization of the brain (Fox and Raichle, 2007). Preliminary support for the reflection of trait-level economic impulsivity in rsFC comes from recent studies that revealed that substance abusers (who tend to have high discounting rates; Perry and Carroll, 2008) exhibited altered rsFC (Ma et al., 2010; Ma et al., 2011). Thus, in the present study, we investigated whether the rsFC between brain regions recruited during the DDT is associated with one's preference for an immediate reward. Moreover, we tested whether the rsFC can predict individuals' discounting rates in the DDT with an independent sample.

The DDT has been shown to activate several neural networks engaged in the valuation process and the choice process (Kable and Glimcher, 2009; Peters and Büchel, 2011), including the networks for reward valuation according to monetary magnitude [e.g., the striatum and the posterior cingulate cortex (PCC)] and time delay (e.g., the medial and lateral prefrontal regions) (Ballard and Knutson, 2009; Pine et al., 2009) and the networks 
a

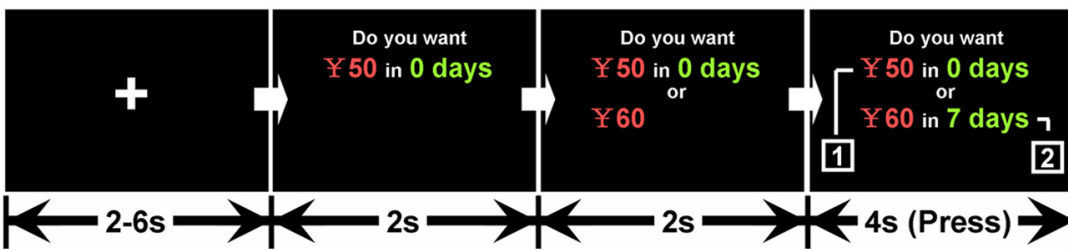

b

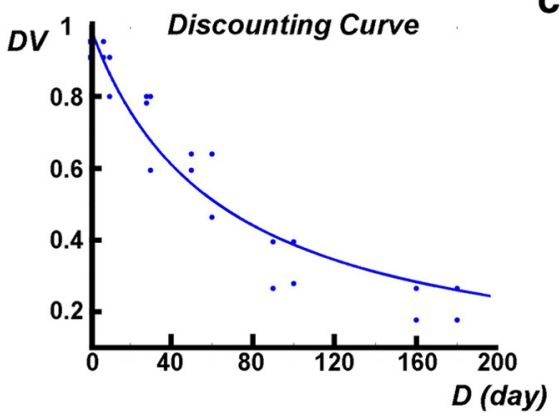

$R T$
$(\mathrm{sec})$

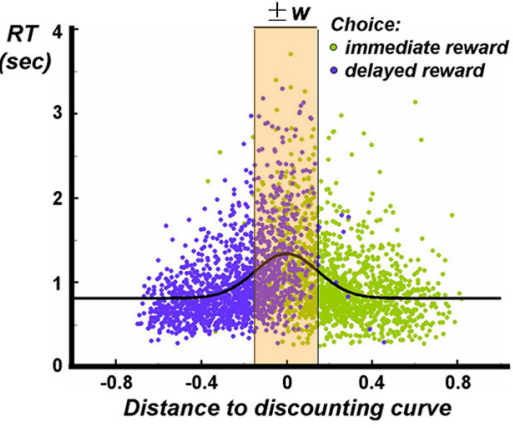

Figure 1. Paradigm of DDT and analysis of behavioral data. $\boldsymbol{a}$, The DDT paradigm. The immediate option (i.e., offering 50 (hinese yuan in $0 \mathrm{~d}$ ) was presented first with a $2 \mathrm{~s}$ duration. After that, the information of monetary magnitude and time delay of the future reward was presented in sequence. Participants made their choices when the second information of the future reward was presented. Intertrial intervals were $2-6 \mathrm{~s}$. All the information during the task was presented in simplified Chinese. $\boldsymbol{b}$, Illustration of the discounting curve from one participant. Steeper discounting curve indicates higher impulsivity for the individual. $c$, Definition of easy and hard trials. Trials located in the area $\pm w$ were defined as hard trials and the other ones as easy trials.

for choice comparison based on reward value [e.g., the frontoparietal network and the dorsal anterior cingulate cortex (dACC)anterior insular cortex (AIC) network; Monterosso et al., 2007; Hoffman et al., 2008]. In addition, task-related activity in the frontoparietal network and the AACC-AIC network is engaged in deliberation and emotional processes, respectively, during decision-making (Sanfey et al., 2006), and the rsFC in the frontoparietal network and dACC-AIC network is correlated with executive task performance and anxiety, respectively (Seeley et al., 2007). The present study investigated whether the rsFC between brain regions recruited during the DDT is associated with preference for immediate reward. Moreover, given the different function roles of the DDT-related neural networks, we examined whether the rsFC within these neural networks is associated with the impulsivity of economic decision-making in a similar vein.

\section{Materials and Methods Experiment I}

Participants

Twenty-three Chinese adults ( 16 males; mean \pm SD age, $22.8 \pm 1.6$ years, ranging from 20 to 25 years; mean \pm SD years of education, $16.5 \pm 1.6$, ranging from 13 to 19 years) participated in experiment I. All participants reported no history of neurological or psychiatric disorders. Written informed consent was obtained before the study. This study was approved by the Human Research Ethics Committee of the University of Science and Technology of China.

\section{Experimental procedure}

$D D T$

The DDT used a jittered single-trial design, similar to Ballard and Knutson (2009) (Fig. 1a). To ensure that each future reward option would be presented only once during the entire task and that each block would cover a similar size of a two-dimensional space for monetary magnitude and time delay of future reward options, future reward options were combined with two sets of monetary magnitudes (M1: 50, 55, 70, 90, 110, 140, 175 Chinese yuan; M2: 50, 60, 68, 75, 100, 125, 150 Chinese yuan) and two sets of time delays (T1: $0,7,30,60,90,180 \mathrm{~d}$; T2: $0,10,28,50,100,160 \mathrm{~d}$ ) as M1T1, M1T2, T1M2, and T2M2, yielding four blocks with 42 trials each. The first and second combinations ("money-to-time" blocks) and the third and fourth combinations ("time-tomoney" blocks) were counterbalanced in terms of the order in which future reward options were presented. The order of the four blocks was counterbalanced across participants.

Each participant performed a short version of the DDT to get familiar with the task $(\sim 5 \mathrm{~min}$ and without any payment) before scanning. During scanning, to ensure incentive compatibility and to verify that discounting measures were reliable, participants were informed that they would receive actual payment (between 50 and 175 Chinese yuan) based on their choice on one randomly drawn trial of the task. Participants came to our laboratory and got the payment within $24 \mathrm{~h}$ after the scanning if the outcome of the selected trial was a monetary gain in $0 \mathrm{~d}$ or in the specified delay for the delayed reward outcome of the selected trial. Participants were paid in cash on the same day if the outcome of the selected trial was immediate monetary gain or after a specified period of delay if the selected trial was a delayed reward. Participants were paid with cash. There was no extra payment to the participants.

\section{MRI data acquisition}

Imaging data were obtained with a $3 \mathrm{~T}$ Siemens Magnetom Trio scanner in the Anhui Provincial Hospital (Hefei, Anhui, China). A circularly polarized head coil was used, with foam padding to restrict head motion. Functional images were acquired with a T2*-weighted echo-planar imaging sequence (echo time, $30 \mathrm{~ms}$; repetition time, $2 \mathrm{~s}$; field of view, 24 $\mathrm{cm}$; matrix, $64 \times 64$ ) with 33 axial slices (slice gap, $0 \mathrm{~mm}$; one voxel: $3.75 \times 3.75 \times 3.7 \mathrm{~mm}$ ), covering the whole brain. Before entering the MR scanner, all the participants were told to keep their heads steady during all scans. Resting-state fMRI data were first acquired with one functional 8 min scan (240 epochs) when participants were asked to keep their eyes closed. This was followed by four functional scans corresponding to the four blocks of the DDT. Each lasted for $8 \mathrm{~min}, 40 \mathrm{~s}$, during which participants performed the DDT. Between every two scans, there was an interval of $\sim 1 \mathrm{~min}$. Corresponding highresolution T1-weighted spin-echo (for anatomical overlay) images and three-dimensional gradient-echo (for stereotaxic transformation) images were also collected.

\section{Association analyses}

\section{Behavioral data analyses}

Each participant's discounting rate was assessed based on the choices made in the DDT (Ballard and Knutson, 2009). For each delay, the choices were defined as 0 for choosing the immediate option and 1 for choosing the future option and then were fit with a logistic function to determine the monetary amount at which there was a 0.5 probability of choosing the immediate versus the future option for the delay, which was the "indifference point" to derive the discounted value (DV) for the delay, where

$$
\mathrm{DV}=\frac{\text { magnitude of immediate reward }}{\text { indifference point }},
$$

and the magnitude of immediate reward was always 50 Chinese yuan in the present study. DVs were fit against the delays with a hyperbolic function (Rodriguez and Logue, 1988),

$$
\mathrm{DV}=\frac{1}{1+k \times D^{\prime}}
$$


called discounting curve (Fig. $1 b$ ), in which $D$ refers to the delay in days, and $k$ is an individual's discounting rate, with larger $k$ indicating higher impulsivity in decision-making. Trials with missed choices were excluded from this processing and from subsequent processing. Trials with response times (RTs) $<100 \mathrm{~ms}$ were also excluded, because these indicated responses before the choice screen being presented. The other trials were defined as hit trials and were included in the analyses.

Easy trials and hard trials were defined to parse the difficulty level of decision-making, similar to Hoffman et al. (2008). For each trial, distance to discounting curve is defined as $D V^{\prime}-D \widehat{V}$, where

$$
\mathrm{DV}^{\prime}=\frac{\text { magnitude of immediate reward (50 yuan) }}{\text { magnitude of future reward }},
$$

and $\widehat{D V}$ is the value on an individual's discounting curve in the corresponding delay. RTs were fit against the distance to each individual's discounting curve (dist) by a normal distribution function:

$$
\mathrm{RT}=C+A \bullet \exp \left(-\frac{1}{2}\left(\frac{\text { dist }}{w}\right)^{2}\right) .
$$

Trials located within the area $\pm w$ were defined as hard trials, and other trials outside this area were defined as easy ones (Fig. 1c). For trials with future reward options involving either 50 yuan or $0 \mathrm{~d}$, which are the same as the immediate reward option in either monetary magnitude or time delay, participants could make their choices by simply comparing the digits of the other information of the options (i.e., comparing time delay for the 50 yuan future reward options, and comparing monetary magnitude for the $0 \mathrm{~d}$ future reward options), without integrating the information of money magnitude and time delay that is considered as an essential process in the DDT (Green and Myerson, 2004). Thus, these trials, labeled as control trials, were considered as the baseline of the decisionmaking demand (Boettiger et al., 2007; Hoffman et al., 2008) and were excluded from hard and easy trials.

\section{fMRI data analysis}

Preprocessing. The imaging data were processed with AFNI (Analysis of Functional Neuroimages) (Cox, 1996) and MATLAB (version 7.6.0.324; MathWorks). Each participant's raw data were corrected for temporal shifts between slices, corrected for motion, spatially smoothed with a Gaussian kernel (full width at half maximum $=4 \mathrm{~mm}$ ), and temporally normalized (for each voxel, the signal of each epoch was divided by the temporally averaged signal). We scanned a total of 27 participants in experiment I, and four were excluded from imaging data analysis as a result of head motion being larger than $2.0 \mathrm{~mm}$. To reduce the effect of head motion and obtain low-frequency fluctuation from resting-state fMRI data, we regressed the motion data out of the time series and then preformed bandpass temporal filtering $(0.01-0.08 \mathrm{~Hz})$ on the residual signals (Birn et al., 2006; Auer, 2008). Then, to further reduce nuisance signals, we regressed out the average signals in the white matter and the CSF (Ma et al., 2010, 2011). The mask of white matter for each participant was determined from the high-resolution structural image using FAST segmentation program of Functional MRI of the Brain software library (www.fmrib.ox.ac.uk). The resultant white matter segmentations were merged by $80 \%$ tissue type probability. The CSF mask for each participant was manually drawn according to the anatomical boundaries of the cortical structures of a standardized Talairach atlas brain (Talairach et al., 1992), transformed onto the image space of the individual, and then modified according to the cortical structures of the individual brain by referencing to the anatomical boundaries in the highresolution three-dimensional structural image. These nuisance signals were used to account for fluctuations unlikely to be relevant to neuronal activity (Fox et al., 2005; Birn et al., 2006; Di Martino et al., 2008). The resultant resting-state fMRI data were then subjected to functional connectivity analysis.

Localizing regions of interest. We first defined the regions of interest (ROIs) using the DDT-related fMRI data for additional rsFC analysis. Because decision-making engages both valuation and choice processes (Kable and Glimcher, 2009; Peters and Büchel, 2011), we used a multiple regression analysis to localize the ROIs related to valuation and choice processes in the DDT, respectively. This analysis included the following psychological regressors: a "money" regressor (defined as 1 to 7 according to the seven levels of monetary magnitudes of future rewards for each scan when the money information was presented and 0 for the other epochs), a "time" regressor (defined as 1 to 6 according to the six levels of time delays of future rewards for each scan when the time information was presented and 0 for the other epochs), two "choice" regressors for hard and easy trials, respectively (defined as 1 for hard/easy trials when participants were required to choose between the options and 0 for the other epochs), and "period" regressors (defined as 1 for period effects for the epochs when the immediate reward was presented or when the first information of future reward was presented or when choice was required, respectively, and 0 for the other epochs). These regressors were convolved by the gamma function to approximate the hemodynamic response of the brain to a stimulus. The regression analysis also included six regressors for head motion and two regressors for linear trends and constant for each scan.

In localization of the ROIs for valuating monetary magnitude in the DDT, each participant's preprocessed time series of the money-to-time scans were concatenated and the regressors were applied in the multiple regression analysis. The resultant $\beta$-value map of the money regressor for each participant was transformed to the Talairach space (resampled voxel size: $2 \times 2 \times 2 \mathrm{~mm}$ ) according to the spatial transformation between the anatomical data and the Talairach space and was then entered into group-level one-sample $t$ test. The group-level $t$ test map was masked by the gray matter of the brain (Ballard and Knutson, 2009) and then merged at the threshold of cluster size 20 voxels $\left(160 \mathrm{~mm}^{3}\right)$ and uncorrected $p<0.005$ for single voxels. Clusters in which the activation showed a positive correlation with monetary magnitude were defined as the money-related ROIs (Ballard and Knutson, 2009). The regression analysis showed activations in brain regions of the mesolimbic cortices [e.g., the striatum, the medial prefrontal cortex (mPFC), and PCC], which were found to be related to processing reward in previous studies (McClure et al., 2004; Kable and Glimcher, 2007; Ballard and Knutson, 2009; Pine et al., 2009), as well as one cluster in the occipital cortex that was, however, excluded in the analysis of resting-state data because the occipital activation might simply arise from differential visual processing of monetary digits. The procedure of localizing the ROIs for valuating time delay was similar to that for the money-related ROIs but used the imaging data in the time-to-money scans as the method implemented by Fitzgerald et al. (2010). Because shorter time delay represents placing a greater value on future reward (Ballard and Knutson, 2009), the timerelated ROIs were defined as the clusters in which the activation for the time regressor showed negative correlation with time delay.

The procedure of localizing the ROIs for the choice process was similar to that for the money-related ROIs (both the money-to-time and timeto-money scans were used). In the group-level one-sample $t$ test, clusters that showed a positive activation in the contrast between choice regressors of hard and easy trials were merged at the significance level of $p<$ 0.05 [familywise error corrected, i.e., uncorrected $p<0.005$ for single voxels and a minimum cluster of 53 voxels $\left.\left(424 \mathrm{~mm}^{3}\right)\right]$. Most of the activated clusters were well separated from each other in the functional statistic map, and only a few activation areas in dorsal part of the PFC were further segmented into subregions because they may be involved in different functions (Aron et al., 2004; Goldstein et al., 2007; Heekeren et al., 2008; Rangel et al., 2008; Rowe et al., 2010) by referencing them to the anatomical boundaries in the Talairach atlas. The resultant ROIs were further separated into two subsets, the frontoparietal network and the dACC-AIC network, because brain regions in the two networks have different functions in decision-making (Sanfey et al., 2006) and are dissociated in their rsFC (Seeley et al., 2007).

In total, we localized the brain regions that were involved in valuating monetary magnitude and time delay, and we labeled them as "the money network" and "the time network," because according to our localization procedure, which was similar to that by Ballard and Knutson (2009), the two networks were dissociated in their functions during the DDT. In addition, the brain regions associated with the choice process were divided into two subsets mainly according to previous evidence of functional differences in decision-making (Sanfey et al., 2006). Thus, the two 


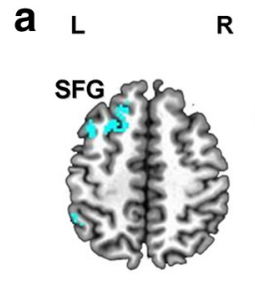

$z=47$

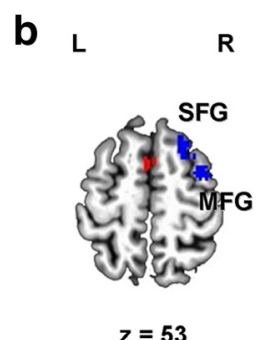

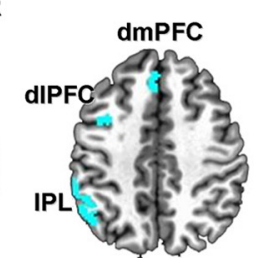

40

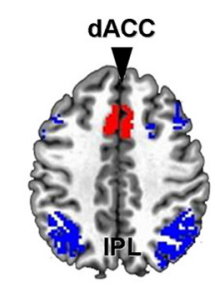

40

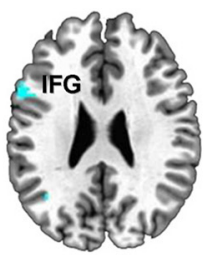

24

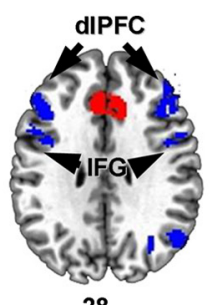

28

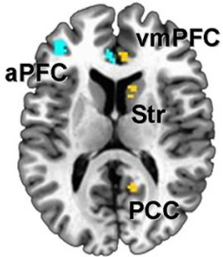

12

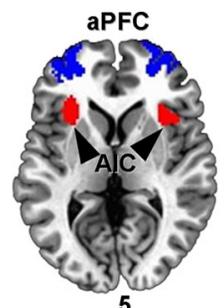

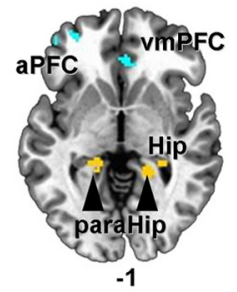

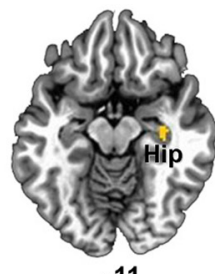

$-11$

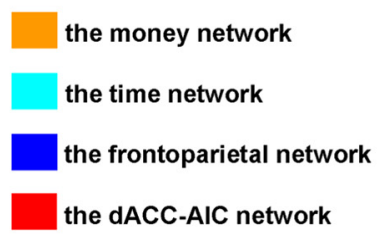

Figure 2. DDT-related brain regions defined by task-related activations. $\boldsymbol{a}$, Brain regions related to the valuation process. The money network consisted of brain regions in which the activity was positively correlated with monetary magnitudes of future reward; the time network consisted of brain regions in which the activity was negatively correlated with time delays of future reward. $\boldsymbol{b}$, Brain regions related with the choice process. These were defied by contrasting hard versus easy trials in the DDT and were further divided into the frontoparietal network and the dACC-AIC network for their different functional roles in decision-making. Str, Striatum; Hip, hippocampus; paraHip, parahippocampus; MFG, middle frontal gyrus.

subsets were labeled more conventionally, as "the frontoparietal network" and "the dACC-AIC network." The four networks were well separated from each other in their containing brain regions (Fig. 2, Table 1). Although the brain regions in the time network were close to those in the frontoparietal network, the majority of the regions in the two networks were dissociated. The subsequent analysis was based on the rsFC within and between these four DDT-related networks.

Defining functional connectivity intensities for the ROIs. The rsFC of the ROIs was analyzed using the algorithm from graph theory (He et al., 2008; Liu et al., 2008; Bullmore and Sporns, 2009) that allows the definition and calculation of the properties of a network involving multiple brain regions along a series of predefined thresholds (Achard and Bullmore, 2007; Stam et al., 2007). This has the advantage of providing a global perspective on the functional organization of the brain and enables the discovery of sensitive thresholds for measuring brain networks. The present study used the parameter known as $K_{\text {cost }}$ in graph theory as a measurement for the functional connectivity intensity (FCI) of the DDT-related brain regions. This parameter measures the sparseness of the connections in a network (Latora and Marchiori, 2003).

For each participant, the ROIs defined in Talairach space were transformed to one's original image space and then modified according to the cortical structures of the individual brain by referencing to the anatomical boundaries in the high-resolution three-dimensional structural image. The preprocessed resting-state fMRI data were averaged within each ROI. Correlation coefficients ( $r$ values) were calculated between each pair of the averaged time series and then transformed to Fisher $z$ values, yielding an $N \times N$ functional connectivity matrix for each participant. We merged each $z$ value matrix with a $T$ value as threshold and obtained an undirected binary graph $G$, consisting of nodes (ROIs) and edges/ functional connections (functional connectivity between pairs of ROIs), with the edge between the $i$ th and the $j$ th node in $G$ defined by the formula

$$
e_{i j}=\left\{\begin{array}{cc}
1 & \text { if }|z(i, j)| \geq T, i \neq j \\
0 & \text { otherwise }
\end{array},\right.
$$

which means that, if the absolute $z$ value of functional connectivity between the $i$ th and the $j$ th ROI is larger than $T$, the edge between the $i$ th and the $j$ th node in graph $G$ exists and vice versa. Because both positive and negative connections contribute to the functional organization of a network (Fox et al., 2005), most previous studies defined the connections between two brain regions using the absolute value of the correlation coefficient. Thus, a larger number of connections surviving in a network could represent more information exchange within that brain network under a certain threshold (He et
Table 1. Regions of interest defined by the brain activations during the delay discounting task

\begin{tabular}{|c|c|c|c|c|c|}
\hline Regions & Brodmann area & Volume $\left(\mathrm{mm}^{3}\right)$ & $x^{a}$ & $y$ & $z$ \\
\hline \multicolumn{6}{|l|}{ Valuation process ${ }^{b}$} \\
\hline \multicolumn{6}{|l|}{ Money } \\
\hline RvmPFC & 24 & 184 & 4.9 & 32.5 & 13.7 \\
\hline R Striatum & & 400 & 10.5 & 10.8 & 8.8 \\
\hline $\mathrm{RPCC}$ & $23 / 31$ & 504 & 10.1 & -54.3 & 10.3 \\
\hline \multirow[t]{2}{*}{ R Hip } & & 248 & 28.4 & -36.0 & -1.4 \\
\hline & & 184 & 32.4 & -18.3 & -11.0 \\
\hline L paraHip & $30 / 30$ & 528 & -17.2 & -36.5 & 1.0 \\
\hline R paraHip & & 272 & 16.6 & -40.7 & -1.3 \\
\hline \multicolumn{6}{|l|}{ Time } \\
\hline LdmPFC & 8 & 808 & -3.3 & 30.5 & 40.3 \\
\hline L vmPFC & 24 & 248 & -2.8 & 33.3 & 9.4 \\
\hline RvmPFC & 24 & 240 & 3.2 & 31.2 & 1.3 \\
\hline LSFG & $6 / 8$ & 1104 & -20.3 & 15.4 & 48.4 \\
\hline L dIPFC & $9 / 46$ & 832 & -35.7 & 8.0 & 42.1 \\
\hline LIFG & 44 & 1032 & -48.5 & 11.7 & 22.9 \\
\hline $\mathrm{LaPFC}$ & 10 & 1576 & -34.8 & 43.0 & 7.9 \\
\hline LIPL & $7 / 39$ & 2384 & -45.2 & -55.0 & 37.8 \\
\hline \multicolumn{6}{|l|}{ Choice process $^{b}$} \\
\hline dACC & $24 / 32$ & 7816 & 1.3 & 20.6 & 34.6 \\
\hline LAIC & 13 & 2192 & -30.5 & 17.7 & 2.5 \\
\hline RAIC & 13 & 2648 & 33.8 & 16.4 & 1.6 \\
\hline RSFG & 8 & 2000 & 22.6 & 13.3 & 50.0 \\
\hline $\mathrm{RMFG}^{\mathrm{C}}$ & 8 & 1208 & 36.9 & 4.8 & 49.4 \\
\hline LdIPFC & $9 / 46$ & 1808 & -41.6 & 21.3 & 32.1 \\
\hline$R \mathrm{dIPFC}^{\mathrm{C}}$ & $9 / 46$ & 3336 & 40.6 & 26.8 & 28.8 \\
\hline LIFG' & $6 / 44$ & 1240 & -43.5 & 5.8 & 30.7 \\
\hline RIFG & $6 / 44$ & 920 & 46.2 & 4.4 & 23.7 \\
\hline LaPFC & 10 & 3288 & -32.3 & 47.8 & 8.1 \\
\hline RaPFC & 10 & 4712 & 30.0 & 51.4 & 7.7 \\
\hline LIPL & $7 / 39$ & 5064 & -35.3 & -57.7 & 40.1 \\
\hline RIPL & $7 / 39$ & 7896 & 38.4 & -61.1 & 38.3 \\
\hline
\end{tabular}

L, Left; R, right; Hip, hippocampus; paraHip, parahippocampus; MFG, middle frontal gyrus.

${ }^{a}$ Coordinates in Talairach space ( $x$, left to right; $y$, posterior to anterior; $z$, inferior to superior).

${ }^{b}$ Regions of the valuation process: positive correlation with money magnitude; negative correlation with time delay; threshold at uncorrected $p<0.005$, cluster size $160 \mathrm{~mm}^{3}$. Regions of the choice process: larger activation in hard trials than in easy trials; threshold at uncorrected $p<0.005$, cluster size $424 \mathrm{~mm}^{3}$, corrected $p<0.05$.

'Segmented regions. 
al., 2008; Liu et al., 2008; Bullmore and Sporns, 2009). The present research also used the absolute value of correlation coefficients to define the global functional organization of a network.

For an individual's functional connectivity matrix, we varied the threshold value $T$ from 0 to the maximum of the absolute $z$ value with a step of 0.05 , which produced a series of graphs from those with all possible edges between the nodes to those with no edges between any nodes. For a graph $G$ under a certain threshold $T$, the FCI within the network was defined as the cost of the graph, $K_{\text {cost }}$, which is the proportion of the total number of edges in the maximum possible number of edges:

$$
\mathrm{FCI}_{\text {within_G }} \equiv K_{\text {cost }}=\frac{1}{N(N-1)} \sum_{i \in G, j \in G} e_{i j},
$$

and could represent the sparseness of functional connections in a graph. Moreover, we further defined the FCI between two networks (e.g., $G$ and $H$ ) as the proportion of survived edges:

$\mathrm{FCI}_{\text {between_G\&H }} \equiv K_{\text {cost_inter }}$

$$
=\frac{1}{N_{G} \times N_{H}} \sum_{i \in G, j \in H} e_{i j} .
$$

Because we defined four brain networks related to the DDT, 10 FCIs were calculated, including the following: (1) three FCIs for networks of the valuation process: the FCI within the money network, the FCI within the time network, and the FCI between the money and time networks; (2) three FCIs for networks of the choice process: the FCI within the frontoparietal network, the FCI within the dACC-AIC network, and the FCI between the frontoparietal and AACC-AIC networks; and (3) four FCIs for networks of the interaction between valuation and choice processes: the FCI between the money and frontoparietal networks, the FCI between the money and dACCAIC networks, the FCI between the time and frontoparietal networks, and the FCI between the time and AACC-AIC networks.

Correlation between FCIs and discounting rates. To investigate the association between the rsFC of the ROIs and individuals' discounting rates, multiple linear regression analyses were conducted along all the $T$ steps with FCIs as independent variables (regressors) and discounting rates [log transformed (Hariri et al., 2006)] as dependent variable. (For some $T$ steps, some FCIs might be zeros or ones across all the participants, so these FCIs did not contribute to the variation of discounting rates, which were excluded from the multiple linear regression model, leaving the other FCIs in the model.)

We determined a proper set of FCIs that could be used as regressors in the regression model in the following way. We subjected all possible combinations within the $10 \mathrm{FCIs}$ (1023 combinations in total) to the multiple linear regression analysis across the thresholds. We used adjusted $R^{2}\left(\operatorname{adj}-R^{2}\right)$ to measure the contribution of an FCI combination to the regression model. This is the ratio of the variance explained by the regressors to the total amount of variance in the dependent variable adjusted for the number of explanatory terms in the model, and this statistic has been shown to be an unbiased estimator of the contribution of a set of explanatory variables $x$ to the explanation of $y$ (Ohtani, 2000).

For each combination of FCIs, we calculated the median of the adj- $R^{2}$ values of the regression models across all the thresholds. If all FCIs reached zeros or ones at a specific threshold, the multiple linear regression model cannot be constructed and the adj- $R^{2}$ values would be zero. The adj- $R^{2}$ values on these thresholds were excluded from the median calculation. Moreover, for some thresholds, the adj- $R^{2}$ values might be negative. This suggests that the explanatory variables explain less variation than random normal variables would. In this case, the adj- $R^{2}$ values would be modified to zero (Legendre, 2008) and passed into the median calculation.

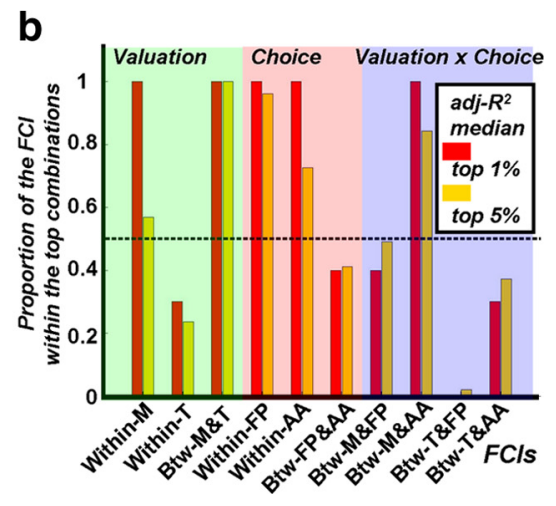

The combination with the largest adj- $R^{2}$ median value consisted of five FCIs, including the FCI within the money network, the FCI between the money and time networks, the FCI within the frontoparietal network, the FCI within the AACC-AIC network, and the FCI between the money and dACC-AIC networks. Meanwhile, these FCIs were contained in both the top $5 \%$ and top $1 \%$ combinations sorted by adj $-R^{2}$ median value for $>50 \%$ (Fig. 3 ). Thus, these five FCIs were used in the multiple linear regression analysis for investigating the association between resting-state FCI of DDT-related brain regions and discounting rate. We also conducted multiple linear regression analyses using all the possible combinations of FCIs to assess whether the FCI-discounting rate association would be a similar direction for the five selected FCIs across different combinations.

\section{Prediction analyses}

The results of association analysis suggest that the rsFC could predict an individual's discounting rate. We used the leave-one-out procedure to test whether the association model could be used to predict individuals' discounting rates (see Fig. $5 a$ ). To do this, we first built a norm model (FCI-discounting rate association involving DDT-related brain regions) based on 22 (the total sample size was 23 in experiment I) participants' resting- and task-state fMRI data and discounting rates. Data from the 22 participants were used to relocalize the DDT-related brain regions and then to reconduct the multiple linear regression analysis between FCIs and discounting rates for the 22 participants along the series of thresholds with the same algorithm used in the association analysis. FCIs used in prediction analysis were fixed as the same five FCIs selected in association analysis. After multiple linear regression analysis along the threshold steps, we constructed a "correlation model" to estimate a single value of discounting rate. For each threshold, the $p$ value for the full model $F$ test of multiple linear regression was transformed to a $z$ value, and then for each participant, each FCI was averaged across all the thresholds (Achard and Bullmore, 2007), weighted by the $z$ values:

$$
\overline{\mathrm{FCI}}_{m}=\frac{\sum_{j}\left(z\left(T_{j}\right) \times \mathrm{FCI}_{m}\left(T_{j}\right)\right)}{\sum_{j} z\left(T_{j}\right)},
$$

where $m$ is for the $m$ th FCI of the five FCIs selected in association analysis, $\mathrm{FCI}(T)$ is the FCI on the threshold $T$, and $z(T)$ is the transformed $z$ value according to the $p$ value for the full model $F$ test of multiple linear regression on the threshold $T$. This algorithm was used to enhance the weight of FCIs from the more significant thresholds. The weighted averaged FCIs were entered into a new multiple linear regression analysis as regressors, 
with discounting rates as the dependent variable, forming the correlation model as the norm model for prediction. Next, FCIs of the 23rd participant (the "to-be-predicted" participant) were calculated using the brain regions defined by data from the other 22 participants and then averaged across all the thresholds weighted by the same $z$ values, which were defined by data from the other 22 participants. Finally, the weighted averaged FCIs of the 23rd participant were substituted into the correlation model to calculate the predicted discounting rate for the participant.

In prediction analysis, both the norm model and FCIs of the to-bepredicted participant were independent of the participant's task-state data, making the predicted discounting rate independent of his/her taskstate data. The predicted discounting rates for all 23 participants were entered into a correlation analysis with their actual discounting rates (both were log transformed).

\section{Correlation between discounting rate and head motion during resting-state $\mathrm{fMRI}$ scan}

Because head motion during scanning might be a trait and thus could be confounded with individual differences (Van Dijk et al., 2012), we conducted a correlation analysis of the participants' head motion during the resting-state scanning and their discounting rates to examine whether head motion confounded the results of the association and prediction analyses. With the motion parameters generated in the motion correction phase of preprocessing, four separate metrics of head motion were calculated, including mean motion, maximum motion, number of movements, and rotation (Van Dijk et al., 2012). All four metrics were entered into correlation analysis with participants' discounting rates (log transformed).

\section{Experiment II}

The prediction analysis in experiment I suggested that the FCI-discounting rate association model could be used to predict an individual's discounting rate. However, there is evidence that the generalizability of an internally validated prediction may be poor for a new sample (Bleeker et al., 2003), and external validation with independent samples is considered to be more relevant than internal validation when the prediction model is applied in another practical setting (Steyerberg et al., 2001; Toll et al., 2008). Thus, we conducted a second experiment to provide external validation with an independent sample of rsFC as a predictor of discounting rate.

\section{Participants}

An independent group of 38 Chinese adults (32 males; mean \pm SD age, $23.5 \pm 1.8$ years, ranging from 20 to 28 years; mean \pm SD years of education, $16.7 \pm 1.6$ years, ranging from 13 to 19 years) participated in experiment II. All participants reported no history of neurological or psychiatric disorders. Written informed consent was obtained before the study. This study was approved by the Human Research Ethics Committee of the University of Science and Technology of China.

\section{Experiment procedure}

Resting-state fMRI data were from another study of our group and were obtained in the same manner as in experiment I. Corresponding highresolution T1-weighted spin-echo (for anatomical overlay) images and three-dimensional gradient-echo (for stereotaxic transformation) images were also acquired. After fMRI data acquisition and outside the scanner, each participant completed the same version of the DDT used in experiment I. Some participants completed other cognitive tasks in the scanner (data will appear elsewhere).

\section{Data analyses}

The DDT-related brain regions and the norm model obtained in experiment I were used to define ROIs in experiment II. The five FCIs selected in association analysis in experiment I were used to predict discounting rates following the same procedure as in experiment I. These participants' predicted discounting rates were entered into a correlation analysis with their actual discounting rates (both were log transformed). Correlations between head motion and participants' discounting rates (log transformed) were also calculated.

\section{Results}

\section{Experiment I}

In experiment I, participants' discounting rates in the DDT ranged from 0.00281 to 0.05529 (mean \pm SD, $0.01872 \pm$ 0.01228 ), similar to previous results (Ballard and Knutson, $2009)$. The proportion of hit trials was high $(98.8 \pm 2.2 \%)$. Within the hit trials, except control trials (for details, see above, Behavioral data analyses), there were $65.7 \pm 4.6 \%$ easy trials and $34.3 \pm 4.6 \%$ hard trials. Participants' choices for immediate and future reward did not significantly differ between easy and hard trials $\left(F_{(1,22)}<0.001, p=0.985\right.$, ANOVA; Fig. $1 c$ ), indicating that the difficulty of the trials was orthogonal to choice of reward.

The analysis of the DDT-related fMRI data yielded the ROIs of four networks. The money network, in which activations were positively correlated with monetary magnitude and thus were engaged in the valuation process, consisted of the right ventral medial PFC (vmPFC), right striatum, right PCC, right hippocampus (two clusters), and bilateral parahippocampus. The time network, in which activations were negatively correlated with time delay, consisted of the left anterior PFC (aPFC), left superior frontal gyrus (SFG), left dorsolateral PFC (dlPFC), left inferior frontal gyrus (IFG), bilateral vmPFC, left dorsal mPFC (dmPFC), and the left inferior parietal lobe (IPL) (Fig. 2a, Table 1). These two networks are similar to those previously observed to be engaged in a similar paradigm (Ballard and Knutson, 2009).

Two networks related to the choice process were obtained in which activations were identified by the contrast of hard versus easy trials during the DDT. The frontoparietal network consisted of the bilateral aPFC, dlPFC, IFG, IPL, the right SFG, and the right middle frontal gyrus. The dACC-AIC network consisted of dACC and the bilateral AIC (Fig. 2b, Table 1). The activation of these two networks is consistent with previous observations using similar paradigms (Monterosso et al., 2007; Hoffman et al., 2008).

Multiple linear regression analysis using the five selected FCIs and individuals' discounting rates in experiment I showed that individuals' discounting rates were positively correlated with the FCI within the money network, the FCI within the dACC-AIC network, and the FCI between the money and dACC-AIC networks. However, discounting rates were negatively correlated with the FCI between the money and time networks and the FCI within the frontoparietal network (Fig. 4a). Multiple linear regression analysis using all the possible combinations of the 10 FCIs showed a pattern similar to that obtained from the above five FCIs (Fig. $4 b$ ), suggesting robust correlations between impulsivity and the five FCIs. These results revealed the association between intrinsic functional organization and individuals' impulsivity in decision-making.

Prediction analysis using the leave-one-out procedure in experiment I revealed that the predicted discounting rates based on the five FCIs selected in association analysis were significantly correlated with actual discounting rates $(r=0.426, n=23, p=0.043$; Fig. $5 b)$, indicating that the norm model based on resting-state activity can predict the discounting rate for a given participant.

\section{Experiment II}

In experiment II, the delay discounting rates of the independent sample ranged from 0.00067 to 0.04302 (mean \pm SD, $0.01439 \pm$ $0.01100)$, similar to that in experiment I. The proportion of hit trials was high $(99.8 \pm 0.3 \%)$. In external validation, the estimated multiple linear regression model used to predict discounting rates was 

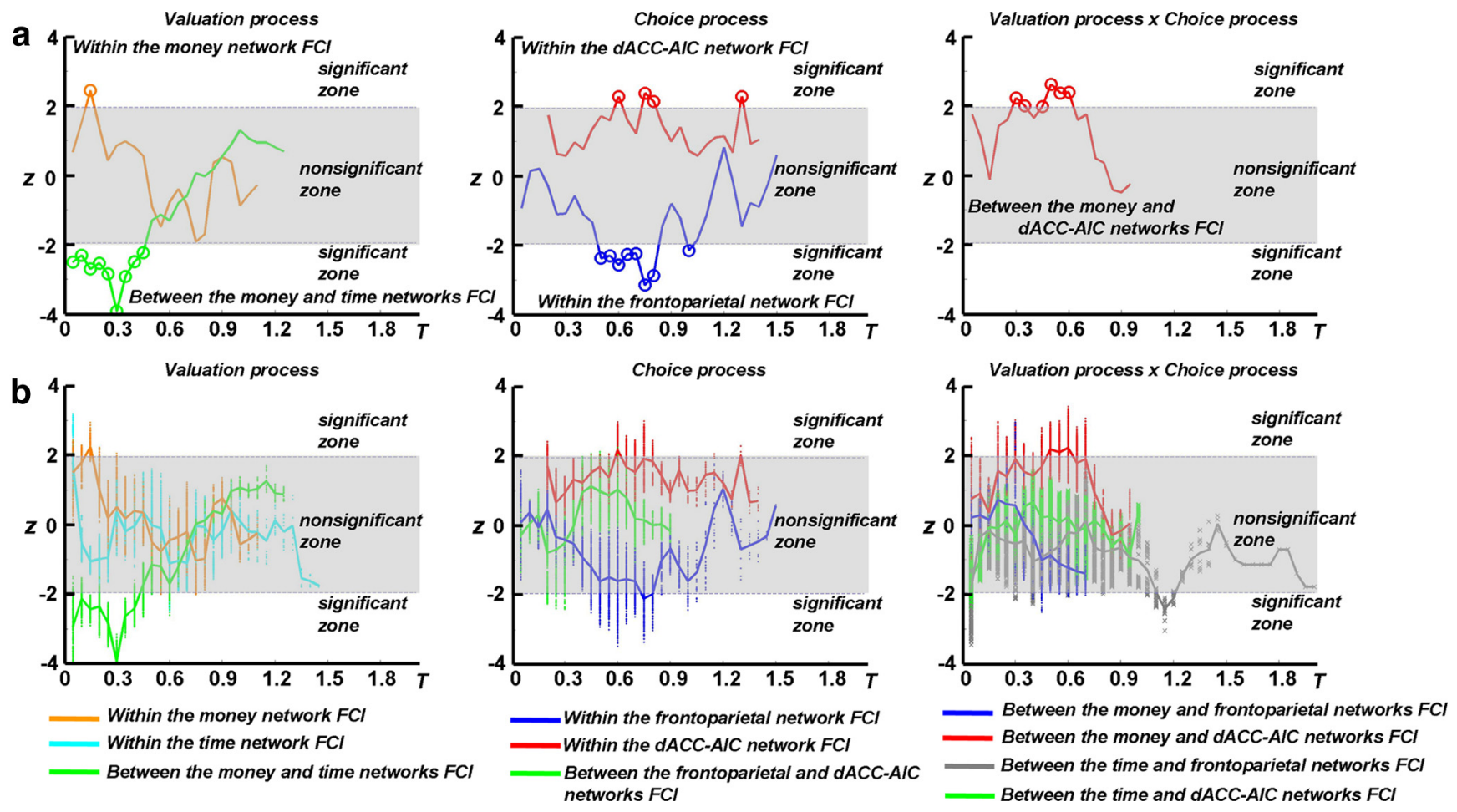

Figure 4. Association between impulsivity and the rsFC of the DDT-related networks. $\boldsymbol{a}$, Multiple linear regressions between individuals' discounting rates and the five FCls selected as the most proper combination. The $t$ values for each regressor are transformed to $z$ scores and plotted against the threshold $T$. Circles represent the $z$ values with $p<0.05$. $\boldsymbol{b}$, Multiple linear regressions between individuals' discounting rates and all the possible $\mathrm{FCl}$ combinations within the $10 \mathrm{FCl}$. Scattered dots represent the $z$ scores for the $t$ values in each multiple linear regression analysis. Lines are the mean $z$ scores of the corresponding FCls.

predicted discounting rate $=$

$2.67 \times \overline{\mathrm{FCI}}($ within_the_money_network)

$-12.15 \times \overline{\mathrm{FCI}}($ between_the_money $\&$ time_networks)

$-2.05 \times \overline{\mathrm{FCI}}$ (within_the_frontoparietal_network)

$$
\begin{gathered}
+1.64 \times \overline{\mathrm{FCI}}(\text { within_the_dACC-AIC_network }) \\
+2.61 \times \overline{\mathrm{FCI}}(\text { between_the_money } \&
\end{gathered}
$$

$$
\text { dACC-AIC_networks) - 3.21, }
$$

where FCI represented the weighted average for the corresponding FCI, and the $\beta$ values in the model were consistent with the association results in experiment I. Based on this model, predicted discounting rates were derived for the participants. A correlation analysis showed that the predicted discounting rates were significantly correlated with participants' actual discounting rates $(r=0.453, n=38, p=0.004$; Fig. $5 c)$. These results constitute external validation and suggest that the norm model of the FCI-discounting rate association can predict the discounting rate for a given participant based on his resting-state fMRI data in an independent sample.

\section{Correlation between head motion and discounting rate}

The correlations between the four metrics of head motion and discounting rates were not significant in either experiment I (all $p$ values $>0.270$ ) or experiment II (all $p$ values $>0.643$ ), indicating that the relationship between resting-state brain function and impulsivity cannot be attributed to individuals' head motion during the resting state.

\section{Discussion}

The previous fMRI studies found associations between impulsive decision-making behavior and DDT-related brain activation (McClure et al., 2004; Boettiger et al., 2007; Kable and Glimcher, 2007) but leave open the question of whether resting-state activity can predict impulsive decision-making. The current work provides the first evidence linking individuals' impulsivity and rsFC in brain regions involved in the DDT. Moreover, we found distinct patterns of association between resting-state FCIs in different neural networks and individuals' impulsivity in decision-making.

The resting-state FCI within the money network was positively correlated with discounting rates. As noted previously, the money network consists of the vmPFC, striatum, PCC, hippocampus, and parahippocampus and is engaged in valuation of both immediate and future rewards (McClure et al., 2004; Kable and Glimcher, 2007; Ballard and Knutson, 2009). Furthermore, hyperactivity of the money network is associated with increased impulsivity during the DDT (Hariri et al., 2006; Mason et al., 2012). Our fMRI findings complement previous research by showing that enhanced rsFC in the money network may significantly influence one's sensitivity to reward information and thus yield high impulsivity.

Interestingly, we found that the FCI between the money and time networks was negatively correlated with discounting rates. Both money and time networks play a key role in the valuation of reward options based on monetary magnitude and time delay (Ballard and Knutson, 2009; Pine et al., 2009). Our FCI results suggest a "default" mode of integration of monetary magnitude and time delay during the resting state that may be associated with impulsivity during decision-making. It is possible that indi- 
a

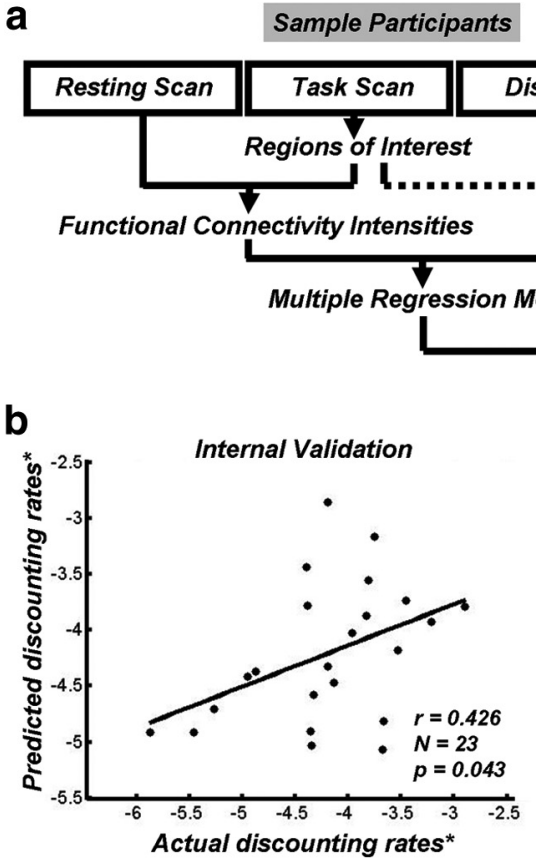

Functional Connectivity Intensities

Predicted Discouting Rate

c.

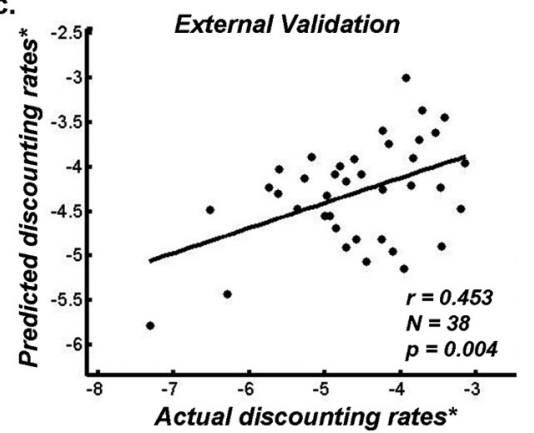

Figure 5. Prediction for individuals' discounting rates by the rsFC. $\boldsymbol{a}$, The sketch map of the prediction analysis for one participant. The resting scan data of the left-out individual were calculated in the brain regions derived from the networks defined from other participants to predict the discounting rate of the left-out individual. $\boldsymbol{b}$, The correlation between actual and predicted discounting rates in experiment $\mathrm{I}$. c, The correlation between actual and predicted discounting rates in experiment II. * indicates log transformed.

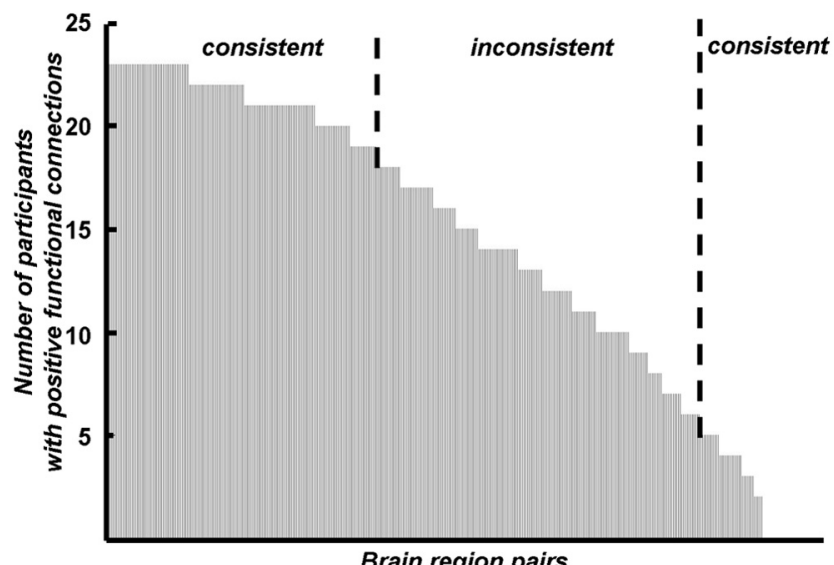

Brain region pairs

Figure 6. Number of participants showing positive functional connections between the DDT-related brain region pairs. For each pair of the DDT-related brain regions (378 pairs in total), the number of participants showing positive connection out of the participants in experiment I ( $n=23$ ) was calculated and sorted in descending order. The sign of connections were consistent across individuals for some brain region pairs (the number of participants with positive connections was either $>18$ or $<5$ of the 23 participants, $\chi^{2}$ test, $p<0.05$ ) but inconsistent for the others.

viduals with stronger FCI between the money and time networks during the resting state may use more frequent information exchange between the two networks during the DDT, and this may result in less impulsive behavior during decision-making.

In addition to the valuation process, the choice process (e.g., self-control) also plays a pivotal role in the DDT (Luo et al., 2009; Figner et al., 2010). Our fMRI results showed that the FCIs within the frontoparietal network and within the dACC-AIC network were correlated with discounting rates in opposite directions. The anterior and dorsolateral regions of PFC, as well as posterior "to-be-predicted" Individual

Resting Scan

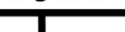

parietal cortex, are consistently engaged in deliberation processes, such as problem solving, planning, and cognitive control (Davidson and Irwin, 1999; Miller and Cohen, 2001; Kim and Lee, 2011). Furthermore, temporarily disrupting the function of lateral PFC increases choice of immediate rewards over larger delayed rewards but does not impact valuation of these rewards, which indicates that impaired self-control could increase impulsivity in the DDT (Figner et al., 2010). Therefore, the negative correlation between the FCI within the frontoparietal network and discounting rates suggests that weakened intrinsic functional organization in the frontoparietal regions may induce insufficient cognitive control during deliberation (a tendency linked to impulsive choices) and thus result in greater preference for immediate reward (a sign of high impulsivity; Patton et al., 1995; Bechara, 2005).

Conversely, the AACC and AIC are the key nodes of the emotional salience network (Seeley et al., 2007; Menon and Uddin, 2010). The insula is a critical neural substrate for conscious urges that reflect an emotional state elicited by external value and corresponding bodily responses, and the insula activation can intensify one's impulsivity (Naqvi and Bechara, 2010). The dACC and AIC are coactivated during emotion-inducing tasks (Sanfey et al., 2003; Bartels and Zeki, 2004; Johnstone et al., 2006), and it has been suggested that the ACC and insular cortex engender the feeling and motivation that constitute emotion (Craig, 2002, 2009). During decision-making, the ACC and insula may be engaged during emotional processes (Sanfey et al., 2006), which are rapid and highly automatic and bias the decision-making behavior toward cognitive less demanding strategies (Botvinick, 2007; Kuo et al., 2009; Rushworth et al., 2011). Thus, the positive correlation between the FCI within the dACC-AIC network and discounting rates observed in our work suggests that enhanced intrinsic functional organization in the dACC and AIC may lead to conscious urges, bias decisions toward less cognitive demand for future planning, and thus lead to the preference for immediate reward.

It is widely accepted that the choice process uses information from the valuation process (Kable and Glimcher, 2009). In line with this perspective, we found a positive correlation between discounting rates and the FCI between the money and dACCAIC networks. The dACC is a prominent target for dopamine projections from neural substrates, such as the striatum (Williams and Goldman-Rakic, 1998). Furthermore, activations in the AIC are modulated by activations in the striatum (Menon and Levitin, 2005). Thus, the dACC-AIC network can be engaged in rapid integration of input regarding the emotional salience of reward stimuli, forming conscious urges based on reward value (Pessoa, 2009; Naqvi and Bechara, 2010; Harl é et al., 2012). Therefore, enhanced FCI between the money and dACC-AIC networks may induce hypersensitivity during the integration of reward information from the valuation process, facilitating conscious urges and leading to high impulsivity. This finding, together with the positive correlation between discounting rates 
and the FCI within the AACC-AIC network, suggests that the dACC-AIC network may serve as a hub linking valuation and choice processes and thus may play an essential role in generating impulsivity. The results from neural networks involved in both valuation and choice processes provide a comprehensive picture of the association between resting-state FCI of DDT-related networks and impulsivity.

The observed association between rsFC and individuals' discounting rates raised the question of whether the resting-state activity can predict an individual's impulsivity in the DDT. This was first verified in experiment I using the leave-one-out procedure. Moreover, experiment II used external validation in an independent sample and showed evidence for a significant correlation between predicted and actual discounting rates. These results indicate that the FCI-discounting rate association model was able to predict an individual's discounting rate. People's impulsivity is routinely evaluated with behavioral assessments (Kirby and Finch, 2010). The results from the two samples in our present study demonstrate that an individual's discounting rate in the DDT can be predicted by his resting-state brain activity, which provides a biomarker and a task-free assessment for impulsivity in economic decision-making.

The current work has several limitations. First, the current work used only the monetary DDT task. It is unknown whether resting-state activity can predict impulsivity in the DDT using other rewards, such as food (McClure et al., 2007), nor is it clear whether these findings generalize to impulsivity related to environmental outcomes and health (Hardisty and Weber, 2009) and impulsivity in other decision-making tasks, such as risk discounting (Christopoulos et al., 2009). Second, like most previous fMRI studies that have used graph theory, the present study only analyzed the absolute value of the functional connections (Achard and Bullmore, 2007; Liu et al., 2008; Bullmore and Sporns, 2009). It is unclear how to relate the sign of connections in graph theory (positive/negative; Fig. 6) to individual difference of impulsivity. Third, because some of the identified neural networks play additional functional roles (e.g., general cognitive abilities for the frontoparietal network; Shamosh and Gray, 2008), the functional significance of these networks in the DDT is unclear. Finally, although we found an association between rsFC and impulsivity in decision-making, the mechanisms by which these patterns of rsFC lead to task-related neural activation and impulsive behavior remain unknown. These questions should be addressed in future research.

In conclusion, we found evidence for the association between impulsivity in decision-making and the rsFC between DDT-related brain regions, which showed distinct patterns for different functional networks. Moreover, the rsFC between DDT-related brain regions was able to predict behavioral impulsivity during the DDT. Our results suggest that the intrinsic functional organization of the brain may underlie individual differences in impulsivity. These findings extend our perspective on the neural basis of impulsivity and provide evidence for a biomarker of impulsivity in economic decision-making.

\section{References}

Achard S, Bullmore E (2007) Efficiency and cost of economical brain functional networks. PLoS Comput Biol 3:e17. CrossRef Medline

Ainslie G (1975) Specious reward: a behavioral theory of impulsiveness and impulse control. Psychol Bull 82:463-496. CrossRef Medline

Aron AR, Robbins TW, Poldrack RA (2004) Inhibition and the right inferior frontal cortex. Trends Cogn Sci 8:170-177. CrossRef Medline

Auer DP (2008) Spontaneous low-frequency blood oxygenation level- dependent fluctuations and functional connectivity analysis of the "resting” brain. Magn Reson Imaging 26:1055-1064. CrossRef Medline

Ballard K, Knutson B (2009) Dissociable neural representations of future reward magnitude and delay during temporal discounting. Neuroimage 45:143-150. CrossRef Medline

Bartels A, Zeki S (2004) The neural correlates of maternal and romantic love. Neuroimage 21:1155-1166. CrossRef Medline

Bechara A (2005) Decision making, impulse control and loss of willpower to resist drugs: a neurocognitive perspective. Nat Neurosci 8:1458-1463. CrossRef Medline

Birn RM, Diamond JB, Smith MA, Bandettini PA (2006) Separating respiratory-variation-related neuronal-activity-related fluctuations in fluctuations from fMRI. Neuroimage 31:1536-1548. CrossRef Medline

Bleeker SE, Moll HA, Steyerberg EW, Donders AR, Derksen-Lubsen G, Grobbee DE, Moons KG (2003) External validation is necessary in, prediction research: a clinical example. J Clin Epidemiol 56:826-832. CrossRef Medline

Boettiger CA, Mitchell JM, Tavares VC, Robertson M, Joslyn G, D'Esposito M, Fields HL (2007) Immediate reward bias in humans: fronto-parietal networks and a role for the catechol-O-methyltransferase $158(\mathrm{Val} / \mathrm{Val})$ genotype. J Neurosci 27:14383-14391. CrossRef Medline

Botvinick MM (2007) Conflict monitoring and decision making: reconciling two perspectives on anterior cingulate function. Cogn Affect Behav Neurosci 7:356-366. CrossRef Medline

Bullmore E, Sporns O (2009) Complex brain networks: graph theoretical analysis of structural and functional systems. Nat Rev Neurosci 10:186198. CrossRef Medline

Christopoulos GI, Tobler PN, Bossaerts P, Dolan RJ, Schultz W (2009) Neural correlates of value, risk, and risk aversion contributing to decision making under risk. J Neurosci 29:12574-12583. CrossRef Medline

Cox RW (1996) AFNI: software for analysis and visualization of functional magnetic resonance neuroimages. Comput Biomed Res 29:162-173. CrossRef Medline

Craig AD (2002) How do you feel? Interoception: the sense of the physiological condition of the body. Nat Rev Neurosci 3:655-666. CrossRef Medline

Craig AD (2009) How do you feel—now? The anterior insula and human awareness. Nat Rev Neurosci 10:59-70. CrossRef Medline

Davidson RJ, Irwin W (1999) The functional neuroanatomy of emotion and affective style. Trends Cogn Sci 3:11-21. CrossRef Medline

Di Martino A, Scheres A, Margulies DS, Kelly AM, Uddin LQ, Shehzad Z, Biswal B, Walters JR, Castellanos FX, Milham MP (2008) Functional connectivity of human striatum: a resting state fMRI study. Cereb Cortex 18:2735-2747. CrossRef Medline

Figner B, Knoch D, Johnson EJ, Krosch AR, Lisanby SH, Fehr E, Weber EU (2010) Lateral prefrontal cortex and self-control in intertemporal choice. Nat Neurosci 13:538-539. CrossRef Medline

Fitzgerald TH, Seymour B, Bach DR, Dolan RJ (2010) Differentiable neural substrates for learned and described value and risk. Curr Biol 20:18231829. CrossRef Medline

Fox MD, Raichle ME (2007) Spontaneous fluctuations in brain activity observed with functional magnetic resonance imaging. Nat Rev Neurosci 8:700-711. CrossRef Medline

Fox MD, Snyder AZ, Vincent JL, Corbetta M, Van Essen DC, Raichle ME (2005) The human brain is intrinsically organized into dynamic, anticorrelated functional networks. Proc Natl Acad Sci U S A 102:9673-9678. CrossRef Medline

Goldstein M, Brendel G, Tuescher O, Pan H, Epstein J, Beutel M, Yang Y, Thomas K, Levy K, Silverman M, Clarkin J, Posner M, Kernberg O, Stern E, Silbersweig D (2007) Neural substrates of the interaction of emotional stimulus processing and motor inhibitory control: an emotional linguistic go/no-go fMRI study. Neuroimage 36:1026-1040. CrossRef Medline

Green L, Myerson J (2004) A discounting framework for choice with delayed and probabilistic rewards. Psychol Bull 130:769-792. CrossRef Medline

Hardisty DJ, Weber EU (2009) Discounting future green: money versus the environment. J Exp Psychol Gen 138:329-340. CrossRef Medline

Hariri AR, Brown SM, Williamson DE, Flory JD, de Wit H, Manuck SB (2006) Preference for immediate over delayed rewards is associated with magnitude of ventral striatal activity. J Neurosci 26:13213-13217. CrossRef Medline 
Harl é KM, Chang LJ, van't Wout M, Sanfey AG (2012) The neural mechanisms of affect infusion in social economic decision-making: a mediating role of the anterior insula. Neuroimage 61:32-40. CrossRef Medline

He Y, Chen Z, Evans A (2008) Structural insights into aberrant topological patterns of large-scale cortical networks in Alzheimer's disease. J Neurosci 28:4756-4766. CrossRef Medline

Heekeren HR, Marrett S, Ungerleider LG (2008) The neural systems that mediate human perceptual decision making. Nat Rev Neurosci 9:467479. CrossRef Medline

Hoffman WF, Schwartz DL, Huckans MS, McFarland BH, Meiri G, Stevens AA, Mitchell SH (2008) Cortical activation during delay discounting in abstinent methamphetamine dependent individuals. Psychopharmacology 201:183-193. CrossRef Medline

Johnstone T, van Reekum CM, Oakes TR, Davidson RJ (2006) The voice of emotion: an FMRI study of neural responses to angry and happy vocal expressions. Soc Cogn Affect Neurosci 1:242-249. CrossRef Medline

Kable JW, Glimcher PW (2007) The neural correlates of subjective value during intertemporal choice. Nat Neurosci 10:1625-1633. CrossRef Medline

Kable JW, Glimcher PW (2009) The neurobiology of decision: consensus and controversy. Neuron 63:733-745. CrossRef Medline

Kim S, Lee D (2011) Prefrontal cortex and impulsive decision making. Biol Psychiatry 69:1140-1146. CrossRef Medline

Kirby KN (2009) One-year temporal stability of delay-discount rates. Psychon Bull Rev 16:457-462. CrossRef Medline

Kirby KN, Finch JC (2010) The hierarchical structure of self-reported impulsivity. Pers Individ Differ 48:704-713. CrossRef Medline

Kuo WJ, Sjöström T, Chen YP, Wang YH, Huang CY (2009) Intuition and deliberation: two systems for strategizing in the brain. Science 324:519522. CrossRef Medline

Latora V, Marchiori M (2003) Economic small-world behavior in weighted networks. Eur Phys J B 32:249-263. CrossRef

Legendre P (2008) Studying beta diversity: ecological variation partitioning by multiple linear regression and canonical analysis. J Plant Ecol 1:3-8. CrossRef

Liu Y, Liang M, Zhou Y, He Y, Hao Y, Song M, Yu C, Liu H, Liu Z, Jiang T (2008) Disrupted small-world networks in schizophrenia. Brain 131: 945-961. CrossRef Medline

Luo S, Ainslie G, Giragosian L, Monterosso JR (2009) Behavioral and neural evidence of incentive bias for immediate rewards relative to preferencematched delayed rewards. J Neurosci 29:14820-14827. CrossRef Medline

Ma N, Liu Y, Li N, Wang CX, Zhang H, Jiang XF, Xu HS, Fu XM, Hu X, Zhang DR (2010) Addiction related alteration in resting-state brain connectivity. Neuroimage 49:738-744. CrossRef Medline

Ma N, Liu Y, Fu XM, Li N, Wang CX, Zhang H, Qian RB, Xu HS, Hu X, Zhang DR (2011) Abnormal brain default-mode network functional connectivity in drug addicts. PLoS One 6:e16560. CrossRef Medline

Mason L, O'Sullivan N, Blackburn M, Bentall R, El-Deredy W (2012) I want it now! Neural correlates of hypersensitivity to immediate reward in hypomania. Biol Psychiatry 71:530-537. CrossRef Medline

McClure SM, Laibson DI, Loewenstein G, Cohen JD (2004) Separate neural systems value immediate and delayed monetary rewards. Science 306: 503-507. CrossRef Medline

McClure SM, Ericson KM, Laibson DI, Loewenstein G, Cohen JD (2007) Time discounting for primary rewards. J Neurosci 27:5796-5804. CrossRef Medline

Menon V, Levitin DJ (2005) The rewards of music listening: response and physiological connectivity of the mesolimbic system. Neuroimage 28 : 175-184. CrossRef Medline

Menon V, Uddin LQ (2010) Saliency, switching, attention and control: a network model of insula function. Brain Struct Funct 214:655-667. CrossRef Medline

Miller EK, Cohen JD (2001) An integrative theory of prefrontal cortex function. Annu Rev Neurosci 24:167-202. CrossRef Medline
Monterosso JR, Ainslie G, Xu J, Cordova X, Domier CP, London ED (2007) Frontoparietal cortical activity of methamphetamine-dependent and comparison subjects performing a delay discounting task. Hum Brain Mapp 28:383-393. CrossRef Medline

Naqvi NH, Bechara A (2010) The insula and drug addiction: an interoceptive view of pleasure, urges, and decision-making. Brain Struct Funct 214:435-450. CrossRef Medline

Ohtani K (2000) Bootstrapping R-2 and adjusted R-2 in regression analysis. Economic Modelling 17:473-483. CrossRef

Patton JH, Stanford MS, Barratt ES (1995) Factor structure of the Barratt impulsiveness scale. J Clin Psychol 51:768-774. CrossRef Medline

Perry JL, Carroll ME (2008) The role of impulsive behavior in drug abuse. Psychopharmacology (Berl) 200:1-26. CrossRef Medline

Pessoa L (2009) How do emotion and motivation direct executive control? Trends Cogn Sci 13:160-166. CrossRef Medline

Peters J, Büchel C (2011) The neural mechanisms of inter-temporal decision-making: understanding variability. Trends Cogn Sci 15:227-239. CrossRef Medline

Pine A, Seymour B, Roiser JP, Bossaerts P, Friston KJ, Curran HV, Dolan RJ (2009) Encoding of marginal utility across time in the human brain. J Neurosci 29:9575-9581. CrossRef Medline

Rangel A, Camerer C, Montague PR (2008) A framework for studying the neurobiology of value-based decision making. Nat Rev Neurosci 9:545556. CrossRef Medline

Rodriguez ML, Logue AW (1988) Adjusting delay to reinforcement: comparing choice in pigeons and humans. J Exp Psychol Anim Behav Process 14:105-117. CrossRef Medline

Rowe JB, Hughes L, Nimmo-Smith I (2010) Action selection: A race model for selected and non-selected actions distinguishes the contribution of premotor and prefrontal areas. Neuroimage 51:888-896. CrossRef Medline

Rushworth MF, Noonan MP, Boorman ED, Walton ME, Behrens TE (2011) Frontal Cortex and Reward-Guided Learning and Decision-Making. Neuron 70:1054-1069. CrossRef Medline

Sanfey AG, Rilling JK, Aronson JA, Nystrom LE, Cohen JD (2003) The neural basis of economic decision-making in the ultimatum game. Science 300:1755-1758. CrossRef Medline

Sanfey AG, Loewenstein G, McClure SM, Cohen JD (2006) Neuroeconomics: cross-currents in research on decision-making. Trends Cogn Sci 10: 108-116. CrossRef Medline

Seeley WW, Menon V, Schatzberg AF, Keller J, Glover GH, Kenna H, Reiss AL, Greicius MD (2007) Dissociable intrinsic connectivity networks for salience processing and executive control. J Neurosci 27:2349-2356. CrossRef Medline

Shamosh NA, Gray JR (2008) Delay discounting and intelligence: a metaanalysis. Intelligence 36:289-305. CrossRef

Stam CJ, Jones BF, Nolte G, Breakspear M, Scheltens P (2007) Small-world networks and functional connectivity in Alzheimer's disease. Cereb Cortex 17:92-99. Medline

Steyerberg EW, Harrell FE, Borsboom G, Eijkemans MJC, Vergouwe Y, Habbema JDF (2001) Internal validation of predictive models: efficiency of some procedures for logistic regression analysis. J Clin Epidemiol 54:774-781. CrossRef Medline

Talairach J, Tournoux P, Musolino A, Missir O (1992) Stereotaxic exploration in frontal epilepsy. Adv Neurol 57:651-688. Medline

Toll DB, Janssen KJ, Vergouwe Y, Moons KGM (2008) Validation, updating and impact of clinical prediction rules: A review. J Clin Epidemiol 61: 1085-1094. CrossRef Medline

Van Dijk KR, Sabuncu MR, Buckner RL (2012) The influence of head motion on intrinsic functional connectivity MRI. Neuroimage 59:431-438. CrossRef Medline

Williams SM, Goldman-Rakic PS (1998) Widespread origin of the primate mesofrontal dopamine system. Cereb Cortex 8:321-345. CrossRef Medline 